\title{
Hybrid Oxidation of Titanium Substrates for Biomedical Applications
}

\author{
Jaroslaw Jan Jasinski * \\ Department of Innovation and Safety Systems, Czestochowa University of Technology CUT, Częstochowa, \\ Poland; jaroslaw.jasinski@wz.pcz.pl \\ * Correspondence: jaroslaw.jasinski@wz.pcz.pl; Tel.: 0048343250865
}

Received: 31 March 2020; Accepted: 14 May 2020; Published: 15 May 2020

\begin{abstract}
Titanium oxidation for biomedical applications is still a challenge in obtaining favorable mechanical and physicochemical properties of thin oxide layers as well as the required high bioactivity. Interesting techniques for $\mathrm{TiO}_{2}$ layers formation are electrochemical, plasma and diffusive methods. Each method aims to create a thin oxide layer characterized by thermal stability and re-passivation in the presence of SBF environment. However, an important aspect here is also phase composition of oxide layers, essential for the osseointegration. Accordingly, research carried out aims to produce such a titanium substrate, where surface zone is $\operatorname{Ti} \alpha(\mathrm{O})$ solid solution formed with Fluidized Bed (FB) diffusion process $\left(640{ }^{\circ} \mathrm{C}, 8 \mathrm{~h}\right)$ and the top layer is $\mathrm{TiO}_{2}$ produced by PVD magnetron sputtering. Effects of such hybrid oxidation on titanium surface properties were investigated with SEM / STEM / RS and Nanoindentation tests. Results showed that hybrid oxidation made it possible to generate favorable synergetic effect between FB and PVD oxide layers and to reduce the stresses at their interface. In turn, variable share of $\mathrm{TiO}_{2}$ phases (rutile + anatase mixture) obtained at the titanium surface allowed for the significant enhancement of hydroxyapatite compounds growth which was confirmed by 14 days Kokubo test.
\end{abstract}

Keywords: titanium oxidation; PVD magnetron sputtering; thin $\mathrm{TiO}_{2}$ layer; bioactivity

\section{Introduction}

Titanium oxide thin layers are still the subject of numerous studies due to their highly interesting properties for biomedicine and implantology, especially for the third-generation biomaterials, which are produced to stimulate specific cell response and tissue regeneration [1-3]. In fact thin $\mathrm{TiO}_{2}$ oxide layers obtained with the use of the several methods as: anodizing, laser treatment PLD, physical methods PVD and diffusion methods, have small thickness and not always good adhesion, which depends on many factors, including surface preparation for the oxidation, phase composition of surface oxides and substrates chemical and strength properties [4-7]. Nevertheless, each method aims to create a passive oxide coating, which is characterized by homogeneity, low thermal conductivity, chemical stability and the ability to re-passivate after being defected in the presence of corrosive environment. The mechanism of titanium oxidation differs from the oxidation of other metals. This is due to stability of the material: $\mathrm{Ti} \alpha-$ stable up to and $\mathrm{Ti}_{\beta}-$ stable over $882^{\circ} \mathrm{C}$. At room temperature on the Ti surface thin $(5-15 \mathrm{~nm})$ passive nanolayer is formed, where in turn oxidation of titanium at high temperature $\left(>400^{\circ} \mathrm{C}\right)$, leads to formation of the crystalline layer with $\mathrm{TiO} /$ inter $\mathrm{Ti}_{2} \mathrm{O}_{3}$ layer and $\mathrm{TiO}_{2}$ layer (rutile or anatase) zone structure. The oxide coating formed at room temperature is stable and adheres well to the substrate, but is too thin. In turn, at high temperatures titanium oxidizes rapidly and forms thick oxide layer which is often porous, poorly bonded (anchored) to the substrate, and thus delaminates and cracks [8-11]. An important role of the oxide layer on the titanium surface in addition to the aforementioned properties is also to provide the required osseointegration process kinetics by forcing the biochemical activity of the layers leading to accelerated interaction with the 
body's tissues [12-16]. Initially, it was thought that the titanium substrates are inert to the body. However, in direct contact with tissues of organisms, titanium can release Ti ions into the body's environment, which causes the occurrence of edema and inflammation, generates health problems of patients and ultimately rejection of the implant. Biocompatibility and bioactivtiy of the titanium is directly related to the physicochemical properties of the substrate surface. To improve the bioactivity of titanium substrates most-known solutions are single-stage surface treatment, and production of multilayers [17-20]. However, surface methods due to the conditions of rapid chemical interaction between the atmosphere and substrate, have very limited influence on oxygen diffusion processes towards the substrates surface layer and formation of $\operatorname{Ti}_{\alpha}(\mathrm{O})$ diffusion layer with good strength properties. Thus, it is difficult to obtain substrates with the following arrangement: $\mathrm{I}$. Ti $\alpha$ substrate / II. $\mathrm{Ti} \alpha(\mathrm{O})$ solid solution / III. thin $\mathrm{TiO}_{2}$ oxide layer, having both stable oxide phases at the surface, low hardness gradient between matrix and layer and reduced state of stress (compressive stresses required) at the interface [21-24]. Accordingly, highly bioactive titanium materials (i.e., third generation metallic biomaterials) might be produced by adequate functionalization of the thin oxide layers (tailored phase composition morphology and adhesion to the substrate) together with controlling of substrate surface stress state and structure. Therefore, the research carried out by Author aims to develop such a titanium substrate, where on diffusion oxide layer $(\operatorname{Ti} \alpha(\mathrm{O})$ solid solution), homogenous, tight and smooth thin $\mathrm{TiO}_{2}$ layer is being formed by surface treatment i.e., PVD magnetron sputtering. Such hybrid method uses the advantages of continuous substrate activation and defect by influence of a fluidized bed aeromechanical factor, and non-equilibrium PVD surface oxidation. There is expectation that combination of $\mathrm{TiO}_{2}$ layers will ensure a synergistic effect on improving titanium substrates biofunctional properties.

\section{Materials and Methods}

The substrates used for hybrid oxidation were made of $\mathrm{Ti}_{\alpha}$ single phase commercially pure titanium manufactured by Kobe Steel LTD in accordance to ASTM 8348, with chemical composition presented in Table 1.

Table 1. The chemical composition of commercially pure titanium used for hybrid oxidation (in accordance with ASTM 8348), [mass \%].

\begin{tabular}{ccccccc}
\hline Material & \multicolumn{6}{c}{ Chemical Composition } \\
\hline KOBE Steel LTD & $\mathrm{O}$ & $\mathrm{N}$ & $\mathrm{C}$ & $\mathrm{H}$ & $\mathrm{Fe}$ & $\mathrm{Ti}$ \\
$\begin{array}{c}\text { Titanium Grade 2 } \\
\text { (ASTM 8348) }\end{array}$ & 0.20 & 0.03 & 0.10 & 0.015 & 0.30 & rest \\
\hline
\end{tabular}

Before hybrid oxidation, substrates were mechanically activated by blasting with a mixture of $\mathrm{Al}_{2} \mathrm{O}_{3}+\mathrm{ZrO}_{2}+\mathrm{Ti}$. Diffusive oxidation was carried out in a fluidized bed $(\mathrm{FB})$ reactor with $\mathrm{Al}_{2} \mathrm{O}_{3}$ grain material at $640{ }^{\circ} \mathrm{C}$ for $8 \mathrm{~h}$ in air atmosphere. After the $\mathrm{FB}$ treatment, substrates were cooled down in air. Further oxidation process was conducted with PVD magnetron sputtering using a $\mathrm{TiO}_{2}$ target, pressure of $3 \times 10^{-2} \mathrm{mbar}, \operatorname{Ar}(99.95 \%)$ atmosphere, constant power mode $\mathrm{P}=350 \mathrm{~W}$, target - substrate distance $60 \mathrm{~mm}$ and deposition time $20 \mathrm{~min}$. Thin $\mathrm{TiO}_{2}$ oxide layers structure and interface were analyzed by scanning electron microscopy SEM (FEI E-SEM XL30 microscope) and scanning transmission electron microscopy STEM (FEI S/TEM TITAN 80-300) method. Surface morphology of the substrates was evaluated by confocal laser scanning microscopy CLSM (OLYMPUS LEXT 4000 microscope). Phase analysis of $\mathrm{TiO}_{2}$ layers was conducted by Raman Spectroscopy RS (Horriba Jobin Yvon LabRAM HR micro-Raman spectrometer equipped with a CCD detector), under excitation wavelength of $532 \mathrm{~nm}$ and the intensity of ca. $10 \mathrm{~mW}$. The acquisition time was set at $30 \mathrm{~s}$. Precise determination of oxide layers' hardness, Young's modulus, elastic and plastic energy was realized with nanoindentation mechanical tests (NANOTEST VENTAGE MICRO MATERIALS Ltd.). Bioactivity response of the titanium substrates was evaluated by 14 days Kokubo test using c-SBF2 solution. It was found that the hybrid oxidation method (FB+PVD) leads to formation of tight, 
homogeneous thin $\mathrm{TiO}_{2}$ layer, which highly improves the bioactivity of titanium surface in the aspect of biomedical applications.

\section{Results and Discussion}

Titanium oxidation realized by two-stage hybrid process (FB+PVD) allowed to produce strength substrates with rutile and anatase $\mathrm{TiO}_{2}$ thin layer at the top surface. First stage oxidation process conducted in fluidized bed (FB), allowed to obtain $\operatorname{Ti}_{\alpha}(\mathrm{O})$ diffusion layer with thickness of $11 \mu \mathrm{m}$ and ca. $2 \mu \mathrm{m}$ nano-porous $\mathrm{TiO}_{2}$ oxide layer. Saturation of titanium with oxygen atoms leads to strengthening of substrate matrix and improves its hardness. Furthermore, fine grain diffusion zone under a nano-porous oxide layer aims to reduce the stress gradient between matrix and $\mathrm{TiO}_{2}$ layer. Second stage oxidation process was PVD magnetron sputtering, which result in a deposition of a thin $\mathrm{TiO}_{2}$ oxide layer with thickness of ca. $0.8-1 \mu \mathrm{m}$. The plasma interaction with the FB substrate involves continuous bombardment of nano-porous $\mathrm{TiO}_{2}$ and enhances local heat transfer to control chemical reactions (physisorption) when forming thin $\mathrm{TiO}_{2}$ PVD layers. Hybrid oxidation also produced stable and fine $\mathrm{FB} \mathrm{TiO} 2 / \mathrm{PVD} \mathrm{TiO}_{2}$ interface with thickness of ca. $600-620 \mathrm{~nm}$ (Figure 1.)

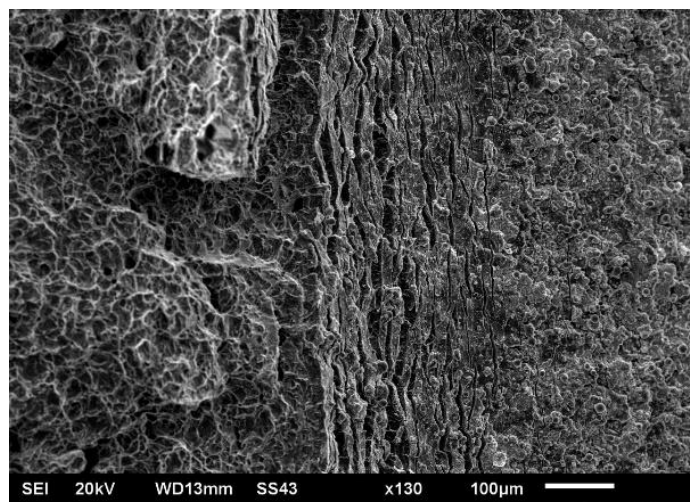

(a)

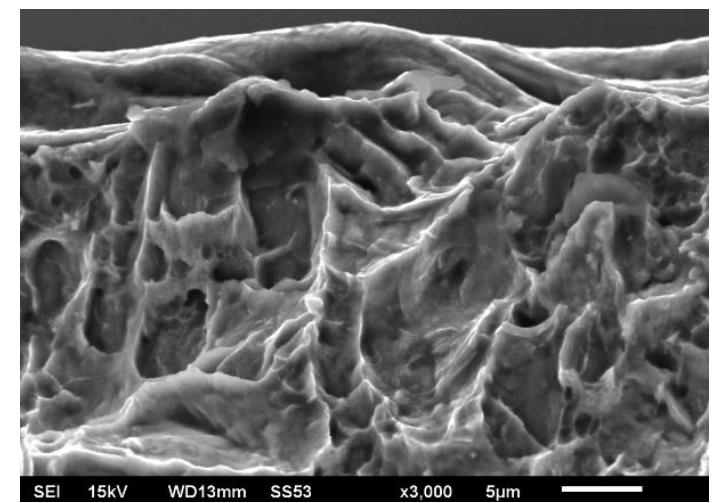

(b)

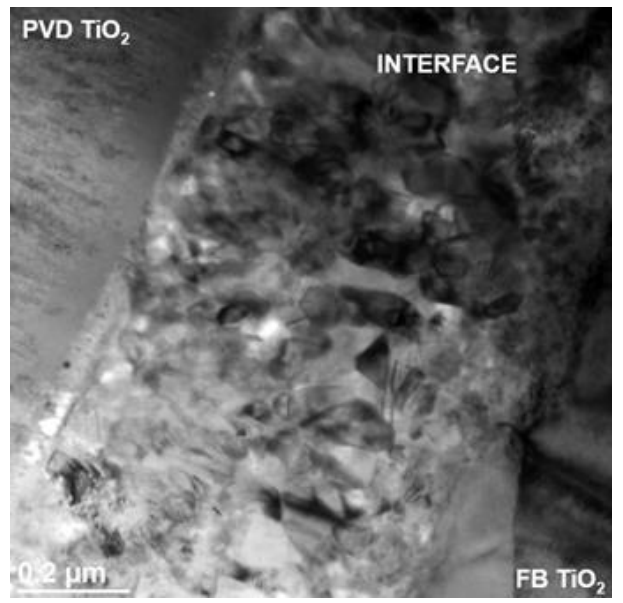

(c)

Figure 1. SEM / STEM images of titanium substrate microstructure and interface after hybrid oxidation (a) $\mathrm{FB} 640{ }^{\circ} \mathrm{C} / 8 \mathrm{~h}$, (b) $\mathrm{FB}+\mathrm{PVD}$ magnetron sputtering (c) $\mathrm{FB} \mathrm{TiO}_{2} / \mathrm{PVD} \mathrm{TiO}_{2}$ interface

At the interface zone there are visible areas of nano-pores size which are free gaps for further anchoring of the $\mathrm{TiO}_{2}$ layers deposited by PVD method. The next step of the research was substrates surface morphology and phase analysis conducted by Confocal Laser Scaning Microscopy and Raman spectroscopy (Figure 2). 

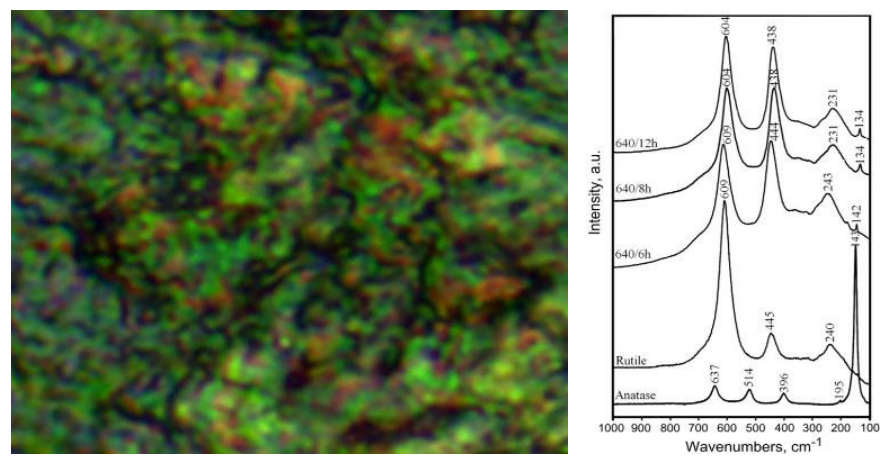

(a)
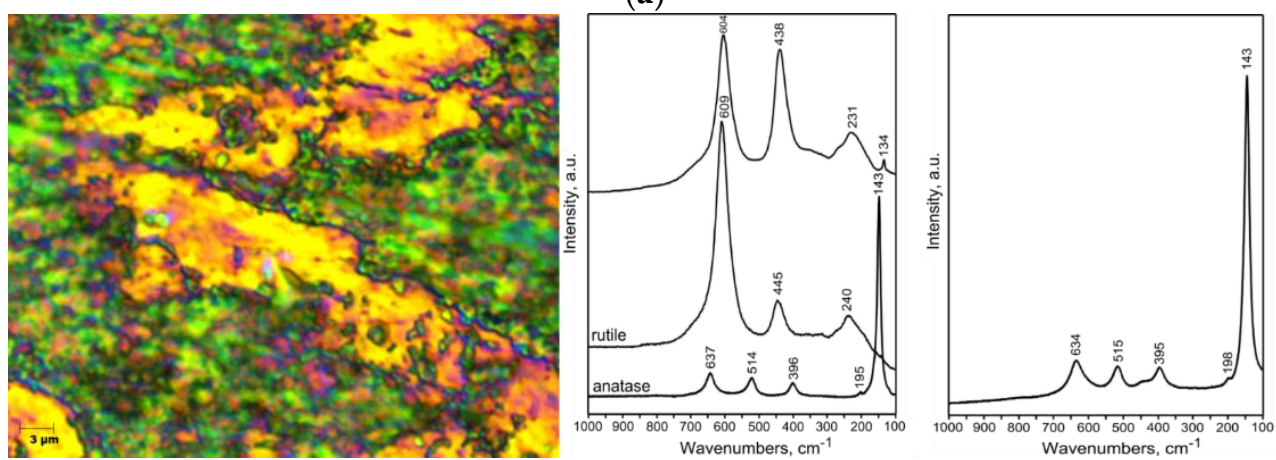

(b)

Figure 2. Confocal Laser Scanning Microscopy image and Raman spectra of titanium surface after hybrid oxidation, (a) FB $640{ }^{\circ} \mathrm{C} / 8 \mathrm{~h}$, (b) FB + PVD magnetron sputtering.

Raman spectra obtained for titanium after FB oxidation showed the presence of the strongest peaks coming from the rutile. Hardly noticeable bands located at wave numbers of $143-146 \mathrm{~cm}^{-1}$ were obtained for anatase phase. However, hybrid oxidation $\mathrm{FB}+\mathrm{PVD}$ showed the presence of $\mathrm{TiO}_{2}$ rutile (wavenumbers: $604 \mathrm{~cm}^{-1}, 438 \mathrm{~cm}^{-1}$ and $231 \mathrm{~cm}^{-1}$ ) and anatase visible band in the range of wavenumbers $143 \mathrm{~cm}^{-1}, 395$ and $515 \mathrm{~cm}^{-1}$. In addition, it was also observed that the bands are shifted towards lower wavenumbers, suggesting the occurrence of compressive stresses in the $\mathrm{TiO}_{2}$ thin layer. The rutile phase of $\mathrm{TiO}_{2}$ layers plays an important role in inducing the apatite deposition as a result of the crystal lattice matching between rutile and apatite. In fact there are some literature data which shows biomedical properties of anatase, including also author's previous works $[25,26]$. Author tries to define and precisely indicate the favorable phase share of the rutile and anatase titanium oxides mixture at the surface, which is promising to has a great influence on bioactive behavior of the substrates. Such phase gradient (between rutile and anatase) has a great influence on osteogenesis and bioactivity of titanium substrates. The next step of the research was nanomechanical investigation of the PVD thin $\mathrm{TiO}_{2}$ oxide layer. The results showed a favorable strength properties of the layers. Series of indentations (in nano and micro scale) was performed on pure titanium (raw substrates) and the specimens after hybrid oxidation. Results of nanoindentation tests are shown in Table 2. 
Table 2. Nanoindentation test results of titanium substrates before and after hybrid oxidation (FB + PVD).

\begin{tabular}{|c|c|c|c|c|c|c|c|c|c|c|}
\hline \multirow{2}{*}{$\begin{array}{c}\begin{array}{c}\text { Substrate } \\
\text { Type }\end{array} \\
\text { Titanium }\end{array}$} & \multicolumn{2}{|c|}{$\begin{array}{c}\text { Hardness, } \\
\text { H [GPa] }\end{array}$} & \multicolumn{2}{|c|}{$\begin{array}{c}\text { Reduced } \\
\text { Young's Modulus, } \\
\text { ER [GPa] }\end{array}$} & \multicolumn{2}{|c|}{$\begin{array}{c}\text { Calculated } \\
\text { Young's Modulus, } \\
\text { E [GPa] }\end{array}$} & \multicolumn{2}{|c|}{$\begin{array}{c}\text { Maximum Depth } \\
{[\mathrm{nm}]}\end{array}$} & \multicolumn{2}{|c|}{$\begin{array}{l}\text { Plastic } \\
\text { Depth } \\
\text { [nm] }\end{array}$} \\
\hline & Value & SD & Value & SD & Value & SD & Value & SD & Value & SD \\
\hline $\begin{array}{c}\text { Grade } 2 \\
\text { (ASTM } \\
8348)\end{array}$ & 9.33 & 4.14 & 160.00 & 60.30 & 148.34 & 55.91 & 204.08 & 57.41 & 167.17 & 54.36 \\
\hline Titanium & Value & SD & Value & SD & Value & SD & Value & SD & Value & SD \\
\hline $\begin{array}{c}\text { hybrid } \\
\text { oxidation } \\
\text { FB+PVD }\end{array}$ & 15.21 & 6.04 & 281.83 & 87.79 & 261.28 & 81.39 & 144.90 & 28.87 & 119.20 & 27.37 \\
\hline
\end{tabular}

Results allowed finding a correlation between mechanical parameters measured in nano and micro-scale for the substrates. Special attention was devoted to the mechanical properties of the $\mathrm{FB}+\mathrm{PVD}$ interface which plays a crucial role in the integrity of the whole hybrid system. Nanoindentation hardness and Young's modulus measured for the $\mathrm{FB}+\mathrm{PVD} \mathrm{TiO}_{2}$ were $\mathrm{H}=15.21 \mathrm{GPa}$ and $\mathrm{E}=261 \mathrm{GPa}$, which are slightly higher values than the results of sputtered $\mathrm{TiO}_{2}$ layers reported in the literature [27]. Nanoindentation results confirmed that hybrid oxidation affects the improvement of titanium surface hardness and strength. From the application as biomaterials point of view of obtained substrates it is necessary to determine their bioactivity. Such important results were obtained after the 14 days Kokubo test in SBF [28,29] (Figure 3).

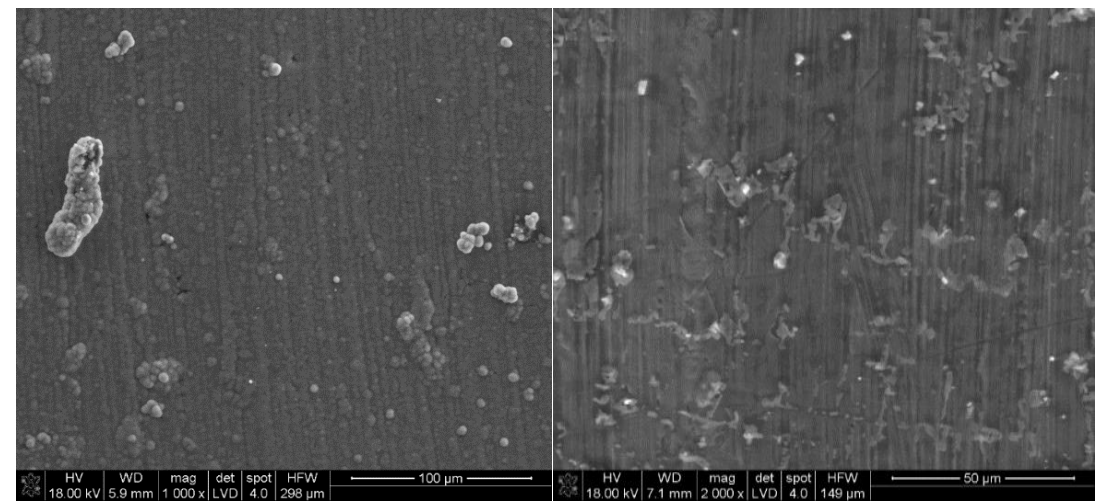

(a)

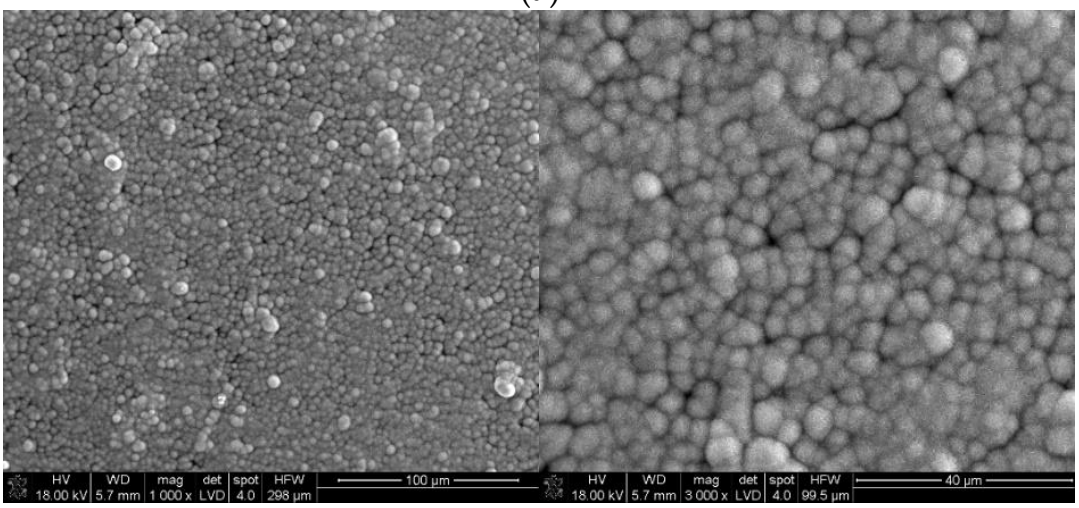

(b)

Figure 3. SEM image of hydroxyapatite growth effect on titanium substrates after hybrid oxidation 14 days SBF Kokubo test, (a) FB $640{ }^{\circ} \mathrm{C} / 8$ h, (b) FB + PVD rutile + anatase phase.

Intensive growth of globular hydroxyapatite compounds was visible at the surface of FB+PVD $\mathrm{TiO}_{2}$ thin rutile / anatase layers. Such improvement in biochemical activity was reached both through stabilization and reducing of stresses at $\mathrm{FB} \mathrm{TiO}_{2} / \mathrm{PVD} \mathrm{TiO}_{2}$ interface, and tailoring of the $\mathrm{TiO}_{2}$ phase 
composition at the surface. Kokubo test results has confirmed that the hybrid oxidation significantly enhances the bioactivity and allows for biofunctional modification of titanium substrates.

\section{Conclusions}

A. Diffusion oxidation in a fluidized bed FB leads to formation of a highly defected Ti $\alpha(\mathrm{O})$ diffusion zone with good strength properties and the nano-porous $\mathrm{TiO}_{2}$. Such system plays role as a foundation for subsequent deposition of thin $\mathrm{TiO}_{2}$ layer by PVD magnetron sputtering.

B. The hybrid oxidation treatment applies two types of the surface activation, I: mechanical as an impact of an aeromechanical factor in FB; II: sputtering with simultaneous oxidation by PVD. Activation increases the number of active centers, and enhances oxygen mass transport finally to form a homogenous thin $\mathrm{TiO}_{2}$ layers. The layers are characterized by high level of homogeneity and resistant to cracking and delayering.

C. In hybrid oxidation, the interface between nano-porous $\mathrm{FB} \mathrm{TiO}_{2}$ and $\mathrm{PVD} \mathrm{TiO}_{2}$ has a favorable state of stress and influences in further formation of a bioactive rutile and anatase mixture which improves the rate of osseointegration.

D. The presented hybrid oxidation is a promising surface treatment for biomedical applications, indicating the directions of forming bioactive layers on titanium substrates. The solution corresponds with the new trends in biomaterials and surface engineering to combine different processing techniques in order to improve the implants and medical devices.

\section{Patents}

Patent no PL 221053 Method for modifying the surface layer of titanium alloy implants P. Podsiad, J.J. Jasinski, J. Jasinski, R. Czyz.

Funding: This research was funded by National Science Centre Poland.

Conflicts of Interest: The author declares no conflict of interest.

\section{References}

1. Rack, H.J.; Qazi, J.I. Titanium alloys for biomedical applications. Mater. Sci. Eng. C 2006, 26, 1269-1277.

2. Kokubo, T.; Kim, H.M.; Kawashita, M.; Nakamura, T. Bioactive metals: Preparation and properties. J. Mater. Sci. Mater. Med. 2004, 15, 99-107.

3. Rahimi, N.; Pax, R.A.; Mac, A.; Gray, E. Review of functional titanium oxides. $\mathrm{I}^{\mathrm{TiO}_{2}}$ and its modifications, Prog. Solid State Ch 2016, 44, 86-105.

4. Zhou, B.; Jiang, X.; Ruiqi Shen, Z.L.; Rogachev, A.V. Preparation and characterization of $\mathrm{TiO}_{2}$ thin film by thermal oxidation of sputtered Ti film. Mater. Sci. Semicond Process 2013, 16, 513-519.

5. Radmanesh, M.; Kiani, A. Bioactivity enhancement of titanium induced by Nd:Yag laser pulses. J. Appl. Biomater. Funct. Mater. 2016, 14, 70-77.

6. Wu, B.; Yu, Y.; Wu, J.; Shchelkanov, I.; Ruzic, D.N.; Huang, N.; Len, Y.X. Tailoring of titanium thin film properties in high power pulsed magnetron sputtering. Vacuum 2018, 150, 144-154.

7. Heinrichs, J.; Jarmar, T.; Wiklund, U.; Engqvist, H. Physical Vapour Deposition and Bioactivity of Crystalline Titanium Dioxide Thin Films. Trends. Biomater. Artif. Organs 2008, 22, 104-110.

8. Shannon, R.D.; Pask, J.A. Kinetics of the anatase-rutile transformation. J Am Ceram Soc 1965, 48(8), 391-398.

9. Aniołek, K.; The influence of thermal oxidation parameters on the growth of oxide layers on titanium, Vacuum 2017, 144, 94-100.

10. Satoh, N.; Nakashima, T.; Yamamoto, K. Metastability of anatase: Size dependent and irreversible anataserutile phase transition in atomic-level precise titania. Sci. Rep. 2013, 3, 1959.

11. Pradhan, S.S.; Sahoo, S.; Pradhan, S.K. Influence of annealing temperature on the structural, mechanical and wetting property of $\mathrm{TiO}_{2}$ films deposited by RF magnetron sputtering. Thin Solid Film. 2010, 518, 69046908.

12. Ochsenbein, A.; Chai, F.; Winter, S.; Traisnel, M.; Breme, J.; Hildebrand, H.F. Osteoblast responses to different oxide coatings produced by the sol-gel process on titanium substrates. Acta Biomater. 2008, 4, 15061517.

13. Barfeie, A.; Wilson, J.; Rees, J.; Implant surface characteristics and their effect on osseointegration. Br. Dent. J. 2015, 218, E9. 
14. Niinomi, M.; Nakai, M.; Hieda, J. Development of new metallic alloys for biomedical applications. Acta Biomater. 2012, 8, 3888-3903.

15. Forsgren, J.; Svahn, F.; Jarmar, T.; Engqvist, H. Formation and adhesion of biomimetic hydroxyapatite deposited on titanium substrates. Acta Biomater. 2007, 3, 980-984.

16. Rosales-Leal, J.I.; Rodríguez-Valverde, M.A.; Mazzaglia, G. et al. Effect of roughness, wettability and morphology of engineered titanium surfaces on osteoblast-like cell adhesion. Colloids Surf. A Physicochem. Eng. Asp. 2010, 365(1-3), 222-229.

17. Yamaguchi, S.; Nath, S.; Sugawara, Y.; Divakarla, K.; Das, T.; Manos, J.; Chrzanowski, W.; Matsushita, T.; Kokubo, T. Two-in-one biointerfaces - antimicrobial and bioactive nanoporous gallium titanate layers for titanium implants Nanomaterials 2017, 7, 229.

18. Ding, Z.; Hu, X.; Yue, P.L.; Lu, G.Q.; Greenfield, P.F. Synthesis of anatase $\mathrm{TiO}_{2}$ supported on porous solids by chemical vapor deposition, Catal. Today 2001, 68, 173-182.

19. Sabetrasekh, R.; Tiainen, H.; Lyngstadaas, S.P.; Reseland, J.; Haugen, H. A novel ultra-porous titanium dioxide ceramic with excellent biocompatibility. J. Biomater. Appl. 2011, 25, 559-580.

20. Sengottuvelan, A.; Balasubramanian, P.; Will, J.; Boccaccini, A.R. Bioactivation of titanium dioxide scaffolds by ALP-functionalization. Bioact. Mater. 2017, 2, 108-115.

21. Li, D.; Ferguson, S.J.; Beutler, T.; Cochran, D.L.; Siting, C.; Hirt, H.P.; Buser, D.J. Biomechanical comparison of the sandblasted and acid-etched and the machined and acid-etched titanium surface for dental implants. J. Biomed. Mater. Res 2002, 60, 325-332.

22. Lubas, M.; Sitarz, M.; Jasinski, J.J.; Jelen, P.; Klita, L.; Podsiad, P.; Jasinski, J. Fabrication and characterization of oxygen -Diffused titanium using spectroscopy method, Spectrochim Acta A 2014, 133, 883-886.

23. Sarvadii, S.Y.; Gatin, A.K.; Kharitonov, V.A.; Dokhlikova, N.V.; Ozerin, S.A.; Grishin, M.V.; Shub, B.R. Oxidation of Thin Titanium Films: Determination of the Chemical Composition of the Oxide and the Oxygen Diffusion Factor. Crystals 2020, 10, 117.

24. Toptan, F.; Alves, A.C.; Pinto, A.M.P.; Ponthiaux, P. Tribocorrosion behavior of bio-functionalized highly porous titanium. J Mech Behav Biomed, 2017, 69, 144-152.

25. He, J.; Zhou, W.; Zhou, X. et al. The anatase phase of nanotopography titania plays an important role on osteoblast cell morphology and proliferation J. Mater. Sci.: Mater. Med. 2008, 19(11), 3465-3472.

26. Jasinski, J.J.; Lubas, M.; Kurpaska, L.; Napadlek, W.; Sitarz, M. Functionalization of Ti99.2 substrates surface by hybrid treatment investigated with spectroscopic methods. J. Mol. Struct. 2018 1164, 412-419.

27. Pang, M.; Bahr, D.; Thin-film fracture during nanoindentation of a titanium oxide film-titanium system. J Mater Res. 2001, 16(9), 2634-2643.

28. Kokubo, T.; Takadama, H. How useful is SBF in predicting in vivo bone bioactivity. Biomaterials 2006, 27, 2907-2915.

29. Oyane, A.; Onuma, K.; Ito, A.; Kim, H.M.; Kokubo, T.; Nakamura, T. Formation and growth of clusters in conventional and new kinds of simulated body fluids. J. Biomed. Mater. Res. 2003, 64A, 339-348.

(C) 2020 by the authors. Submitted for possible open access publication under the terms and conditions of the Creative Commons Attribution (CC BY) license (http://creativecommons.org/licenses/by/4.0/). 